\title{
VARIABILIDADE DA PRECIPITAÇÃO EM SUMÉ E SÃO JOÃO DO CARIRI E SUAS CONSEQUÊNCIAS NA AGROPECUÁRIA
}

\author{
SENA, Jaricélia Patrícia de Oliveira Sena - jariceliasena@hotmail.com \\ Universidade Federal de Campina Grande/UFCG \\ MORAES NETO, João Miguel - j.miguel.moraes@hotmail.com \\ Universidade Federal de Campina Grande/UFCG \\ LUCENA, Daisy Beserra - daisylucena@yahoo.com.br \\ Universidade Federal da Paraíba/UFPB
}

\begin{abstract}
RESUMO: A precipitação pluviométrica é um importante elemento do ciclo hidrológico, principalmente nas regiões que sofrem com a irregularidade espacial e temporal, além de ser uma das variáveis do clima que exerce maior influência na qualidade ambiental, interferindo em diversos setores da sociedade. Objetivou-se investigar o comportamento da precipitação em anos extremos, a influência dos oceanos nos totais anuais pluviométricos e seus impactos na agropecuária. Foram selecionados os municípios de Sumé e São João do Cariri localizados na região semiárida do Estado da Paraíba, região esta que apresenta os menores totais pluviométricos do Estado. Os dados pluviométricos mensal, foram obtidos na Agência Executiva de Gestão das Águas do estado da Paraíba (AESA), compreendendo o período de 1995 a 2015 (21 anos de dados). A partir da técnica dos quantis, foi possível realizar a classificação dos eventos de pluviometria extrema. Após a identificação dos anos de eventos secos e chuvosos, estes foram relacionados com as fases do El Niño-Oscilação Sul (ENOS) e do Gradiente meridional inter-hemisférico da temperatura da superfície do mar (GRADM), e constatou-se que, os mesmos influenciam os eventos de precipitação, e como consequência afetam os quantitativos da produção agropecuária.
\end{abstract}

PALAVRAS-CHAVES: eventos extremos, influência dos oceanos, agricultura, pecuária.

\section{VARIABILITY OF PRECIPITATION IN SUMÉ AND SÃO JOÃO DO CARIRI AND ITS CONSEQUENCES IN FARMING}

ABSTRACT: Precipitation is an important element of the hydrological cycle, especially in regions that suffer from spatial and temporal irregularity, as well as being one of the climate variables that exerts the greatest influence on environmental quality, interfering in several sectors of society. The objective was to investigate the precipitation behavior in extreme years, the influence of the oceans on annual rainfall totals and their impacts on agriculture. The municipalities of Sumé and São João do Cariri were located in the semi - arid region of the State of Paraíba, which presents the lowest total rainfall of the State. The monthly rainfall data were obtained from the Executive Agency for Water Management of the State of Paraíba (AESA), covering the period from 1995 to 2015 (21 years of data). From the quantiles technique, it was possible to classify extreme rainfall events. After identifying the years of dry and rainy events, these were related to the El Niño-Southern Oscillation (ENSO) and Southern Inter-Hemispheric Sea Surface Temperature (GRADM) phases, and it was found that the precipitation events, and as a consequence affect the quantitative of agricultural production.

KEYWORDS: extreme events, influence of the oceans, agriculture, livestock.

\section{INTRODUÇÃO}

A precipitação pluviométrica é um importante elemento do ciclo hidrológico, assim como, uma das variáveis do clima que exerce maior influência na qualidade ambiental, social e econômica, afetando direta ou indiretamente toda a sociedade (Coan et al., 2015). Também é um dos elementos principais 
para a classificação climática de uma região, pois, sua variabilidade integrada a outros elementos climáticos, como a temperatura, ocasiona uma alteração no comportamento geral do clima local (Pereira et al., 2011).

Levando em consideração que a precipitação é um elemento natural e complexo, percebe-se a necessidade de uma análise mais detalhada, para que possa ser alcançado o máximo aproveitamento de informações sobre a caracterização de sua variabilidade e anomalia, tanto em relação ao tempo quanto ao espaço.

No estado da Paraíba, onde $86,6 \%$ de sua área está inserida na região semiárida, é perceptível a grande variabilidade da precipitação anual, desde totais acumulados inferiores a $800 \mathrm{~mm} / \mathrm{ano}$, a exemplo do Cariri Paraibano, até totais precipitados superiores a $1700 \mathrm{~mm} / \mathrm{ano}$, como no Litoral do Estado. É um estado que apresenta elevada variabilidade interanual da precipitação, com anos extremamente secos e outros chuvosos (Marengo et al., 2011).

O foco do estudo será o Cariri paraibano que apresenta os maiores volumes pluviométrico acumulado no período chuvoso, de fevereiro a abril (correspondendo a $49 \%$ do total anual) e o período seco nos meses de setembro a novembro, onde é registrado um volume pluviométrico pequeno ou inexistente (Sena et al., 2012). O Cariri paraibano é uma região fisiográfica de condições climáticas de semiaridez, com fauna e flora pouco diversificada, devido a influência do clima, sendo este um fator limitante para o desenvolvimento da vida local.

As principais atividades agrícolas da região do Cariri paraibano são: feijão, milho, mandioca e batata-doce, são culturas de sequeiro e são primordiais para a economia familiar. A seca em anos seguidos é um dos problemas enfrentados por agricultores, dificultando ao extremo a produção agrícola no Cariri. A agricultura sempre cumpriu um papel importante na economia da região, embora fosse uma atividade complementar à pecuária (Souza, 2008).

A pecuária é uma atividade dominante no Cariri desde a época da sua colonização. Uma das atividades tradicional no Cariri é a criação de caprinos e ovinos, pois são animais bastante resistentes e se adaptam às condições do ambiente.

Nas últimas décadas os eventos extremos - entenda como evento extremo valores discrepantes de uma variável em relação ao seu estado climático médio - tem aumentado ao redor do mundo (Coan et al., 2015), dentre os quais se podem citar: períodos de estiagens, inundações, deslizamentos, dentre outros. Estes eventos têm afetado diversas cidades brasileiras causando múltiplos e constantes impactos, tais como: elevado número de mortes, feridos, desabrigados, proliferação de doenças, perdas econômicas, impactos ao meio ambiente e vários outros. Esses impactos são ainda mais susceptíveis para a população que vive em situação de vulnerabilidade (Loureiro et al., 2014).

Conforme afirma Zanella (2006), eventos extremos de chuva (precipitação) são aqueles, cujos valores atingem $60 \mathrm{~mm} / 24 \mathrm{~h}$ ou mais, bem como a somatória de chuvas de três dias (72h) consecutivos que totalizem valores iguais ou superiores a $60 \mathrm{~mm}$. Já Calvetti et al. (2009), define chuvas extremas a partir da categoria hidrológica, aquela para os quais valores 
superem $50 \mathrm{~mm}$ em 24h. Todavia, Barbosa (2007) diz que os eventos extremos de chuva são aqueles em que os totais num certo período - seja anual, sazonal, diário ou outro - apresentaram desvios de chuva superiores ou inferiores ao comportamento habitual da área no período analisado.

Os eventos extremos, principalmente ausência de precipitação - seca severas - que assolam a região semiárida, tem sido por séculos um grande agravante para a população. A seca severa e chuvas intensas não são tão raras e, impactam diretamente à produção agropecuária, como mostrado nos trabalhos de Farias et al. (2017), Nóbrega et al. (2014), Marengo (2006) dentre outros. Sendo assim, as pesquisas que visem compreender estes eventos ajudarão na análise dos impactos deflagrados pelos mesmos nas atividades agropecuárias existente no estado.

Em grande escala Molion \& Bernardo (2002) afirmam que a variabilidade interanual da distribuição de chuvas no Nordeste Brasileiro (NEB) nas escalas espacial e temporal, está diretamente relacionada com a influência dos Oceanos Pacífico e Atlântico.

Xavier et al. (2003), Santos e Brito (2007), mostraram que a precipitação sobre o NEB é bastante sensível a extremos de TSM no Oceano Pacífico Equatorial associado ao evento El Niño, Oscilação Sul (ENOS) (Ropelewski e Halpert, 1987), assim como, as anomalias da TSM do Atlântico Tropical associado ao Dipolo do Atlântico. Esses sistemas de interação oceanoatmosfera são os principais controladores na variabilidade interanual de chuvas sobre o NEB.

Wainer (2010) estudando o impacto do oceano Atlântico na variabilidade climática do Brasil, afirma que a Temperatura da Superfície do Mar (TSM), desempenha influência principalmente, sobre a precipitação no nordeste brasileiro. Silva et al. (1999), estudaram as influências de cada oceano no regime de chuva do Estado da Paraíba e concluíram que, o Oceano Atlântico tem maior influência em relação ao oceano Pacífico Tropical.

Nesse contexto, objetivou-se com este trabalho analisar os anos extremos de precipitação, verificar a influência dos oceanos nos totais anuais pluviométricos e seus impactos na agropecuária em dois municípios (Sumé e São João do Cariri) na região do Cariri Paraibano.

\section{MATERIAL E MÉTODOS}

Para o desenvolvimento do estudo, foram selecionados dois municípios, dentre os 29 que compõe a região do Cariri Paraibano, devido à falta de informações dos dados pluviométricos. Os municípios em estudo são Sumé (Cariri Ocidental), com área territorial de $838,07 \mathrm{Km} 2$, população de 16.060 habitantes e uma densidade demográfica de 19,16 habitantes/Km2 e São João do Cariri (Cariri Oriental), com uma área total de $653,09 \mathrm{Km} 2$, sendo ocupada por 4.344 habitantes e uma densidade demográfica de 6,65 habitantes/Km2, segundo o último censo IBGE (2010) (Figura 1). 


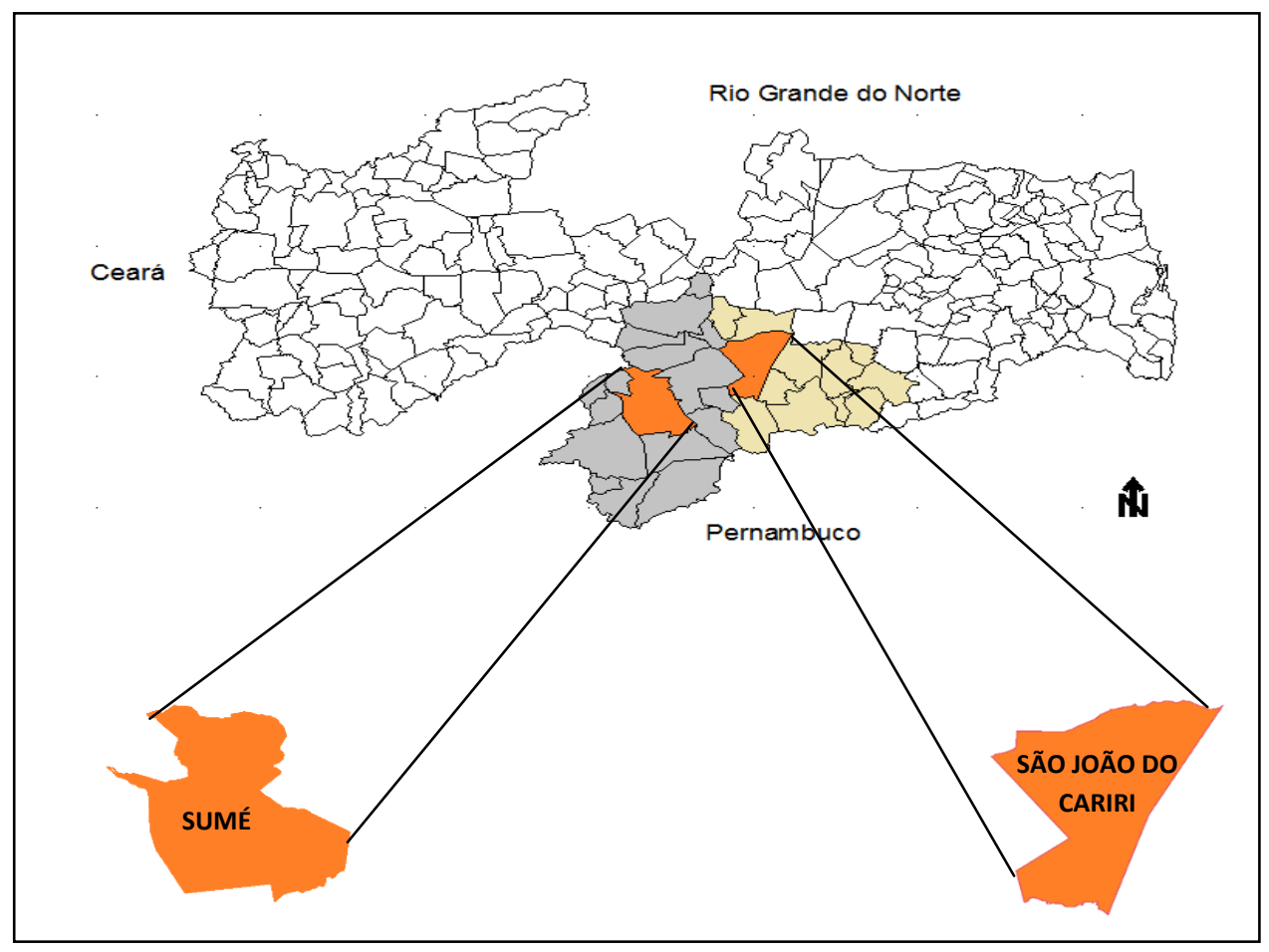

Figura 1 - Mapa da Divisão Política do Estado da Paraíba, localização das áreas de estudo no Estado da Paraíba. Fonte: Adaptado do IBGE (2016).

No Cariri, embora as precipitações pluviais mensais não sejam elevadas, segundo Moura et al. (2007) a precipitação é extremamente importante para as regiões semiáridas pois determinam o sucesso da atividade agrícola e pecuária e consequentemente a sobrevivência das famílias. A época mais chuvosa do ano concentra-se nos seis primeiros meses e o período menos chuvoso (seco) correspondem aos meses de setembro a novembro (Tabela 1). Percebe-se que Sumé apresenta uma pluviometria anual maior que São João do Cariri corroborando com os trabalhos de Sena et al. (2014) e Alves et al. (2012), devido à localização na porção Ocidental e Oriental do Cariri, respectivamente. 
Tabela 1 - Distribuição mensal da pluviometria para o Cariri Ocidental e Oriental.

\begin{tabular}{cc|cc}
\hline \multicolumn{2}{c|}{ CARIRI OCIDENTAL } & \multicolumn{2}{c}{ CARIRI ORIENTAL } \\
\hline \multicolumn{2}{c}{ MÉDIA DA PLUVIOMETRIA (mm) } \\
\hline \multicolumn{2}{c}{ SUMÉ } & SÃO JOÃO DO CARIRI \\
Janeiro & 43,8 & Janeiro & 25,8 \\
Fevereiro & 77,4 & Fevereiro & 54,0 \\
Março & 132,9 & Março & 90,4 \\
Abril & 130,2 & Abril & 81,2 \\
Maio & 58,6 & Maio & 48,1 \\
Junho & 42,4 & Junho & 31,0 \\
Julho & 23,4 & Julho & 22,8 \\
Agosto & 9,2 & Agosto & 6,2 \\
Setembro & 5,0 & Setembro & 1,8 \\
Outubro & 6,4 & Outubro & 5,3 \\
Novembro & 11,9 & Novembro & 6,2 \\
Dezembro & 18,1 & Dezembro & 12,0 \\
\hline TOTAL & $\mathbf{5 8 4 , 9}$ & TotAL & $\mathbf{3 8 1 , 4}$ \\
\hline
\end{tabular}

Fonte: AESA, 2018.

Os dados pluviométricos foram provenientes da Agência Executiva de Gestão das Águas do Estado da Paraíba (AESA), compreendendo o período de 1995 a 2015 (21 anos de dados).

Para a análise da influência dos oceanos sobre a precipitação na região foram utilizados dados de anomalias mensais da Temperatura da Superfície do Mar (TSM) sobre o Pacífico e Atlântico, obtidos no site de Climate Prediction Center / National Oceanic and Atmospheric Administration (CPC/NOAA).

Informações sobre as culturas desenvolvidas na região e a produção agrícola anual e pecuária, foram obtidas no sítio do Instituto Brasileiro de Geografia e Estatística (IBGE), através do link: banco de dados Séries Estatísticas \& Séries Históricas. Na agricultura, foram obtidas a quantidade de área plantada e colhida para as culturas do feijão e do milho. Na pecuária a quantidade de cabeças de bovinos, caprinos, ovinos e suínos.

Inicialmente foi aplicada a técnica dos quantis para seleção dos eventos extremos de precipitação para os dois municípios em estudo. A vantagem em se utilizar a técnica dos quantis, consiste em ser imune a eventual discrepância da função densidade de probabilidade, descrevendo o fenômeno aleatório, que em nosso caso é a chuva (Xavier et al., 2007)

Os quantis possibilitam estabelecer ou delimitar faixas com regimes de chuvas diferenciados, tais como: extremamente seco (ES), muito seco (MS), seco (S), normal (N), chuvoso (C), muito chuvoso (MC) e extremamente chuvoso (EC). Para melhor entendimento da utilização da técnica estatística e a noção de quantis, supõe-se que a chuva em um determinado local, acumulada 
em certo intervalo (mês, bimestre, trimestre, quadrimestre, semestre, ou até mesmo o ano inteiro etc.), com respeito à anos consecutivos, possa ser representada, em termos, por uma variável aleatória contínua (Sena et al., 2014).

Para a realização deste estudo os quantis utilizados referem-se às probabilidades de 0,$05 ; 0,15 ; 0,35 ; 0,65 ; 0,85 ; 0,95$. Dessa forma, serão determinados e classificados limites de intensidade para a chuva anual no Cariri Paraibano, relacionada às ordens quantílicas (Tabela 2).

Após a seleção da classificação da pluviometria pelo método dos quantis, foi analisado o comportamento da precipitação (anos secos e chuvosos) com relação ao fenômeno que estava configurado sobre os Oceanos (El Niño e La Niña e GRADM). Para a seleção dos eventos foi utilizada a região do Niño 3.4, por ser um dos índices mais difundidos operacionalmente para fins de monitoramento e previsão dos eventos ENOS e suas teleconexões (TRENBERTH, 1997). Os anos de El Niño e La Niña foram selecionados tendo como base a relação do $\mathrm{CPC} / \mathrm{NOAA}$ e se baseiam num limiar de $+/-0,5^{\circ} \mathrm{C}$ para o Índice Niño (média móvel de 3 meses das anomalias do ERSST.v2 TSM na região do Niño 3.4).

Tabela 2 - Classificação das categorias e probabilidades da precipitação anual relacionada às ordens quantílicas para a região do Cariri Paraibano.

\begin{tabular}{lc}
\hline \multicolumn{1}{c}{ Categorias } & Probabilidade \\
\hline Extremamente Seco (ES) & $\mathrm{p}(\mathrm{x})<\mathrm{Q}_{0,05}$ \\
Muito Seco (MS) & $\mathrm{Q}_{0,05} \leq \mathrm{p}(\mathrm{x})<\mathrm{Q}_{0,15}$ \\
Seco (S) & $\mathrm{Q}_{0,15} \leq \mathrm{p}(\mathrm{x})<\mathrm{Q}_{0,35}$ \\
Normal (N) & $\mathrm{Q}_{0,35} \leq \mathrm{p}(\mathrm{x})<\mathrm{Q}_{0,65}$ \\
Chuvoso (C) & $\mathrm{Q}_{0,65} \leq \mathrm{p}(\mathrm{x})<\mathrm{Q}_{0,85}$ \\
Muito Chuvoso (MC) & $\mathrm{Q}_{0,85} \leq \mathrm{p}(\mathrm{x})<\mathrm{Q}_{0,95}$ \\
Extremamente Chuvoso (EC) & $\mathrm{p} \geq \mathrm{Q}_{0,95}$ \\
\hline
\end{tabular}

Fonte: Adaptada de Almeida et al. (2013).

Foram considerados anos de ocorrência do GRADM positivo aqueles anos em que o índice apresentou valor acima de $0,5^{\circ} \mathrm{C}$ e negativo os valores abaixo de $-0,5^{\circ} \mathrm{C}$, durante pelo menos dois meses consecutivos entre os meses de janeiro a junho (Lucena et al., 2011). Em seguida foi realizado estudos de caso partindo de anos extremos seco e chuvoso, e a influência dos oceanos, verificou-se possíveis impacto na agricultura, como diminuição ou aumento (área plantada e colhida) e na pecuária foi comparado a perda ou ganho do total anual de cada rebanho.

\section{RESULTADOS E DISCUSSÃO}

A classificação do total pluviométrico de acordo com as ordens quantílicas para o município de Sumé e São João do Cariri, pode ser observada na Tabela 3. Para o município de Sumé, os resultados mostram que um ano ES, determinado pelo quantil $\mathrm{Q}(0,05)$, apresenta precipitação anual inferior a $27 \mathrm{~mm}$, para um ano EC, a precipitação anual deverá ser maior ou igual a 890,20 mm, delimitado pelo quantil Q $(0,95)$. Já para São João do Cariri, os resultados mostram que um 
ano ES apresenta precipitação anual inferior a 124,80 mm, e um ano EC quando a precipitação for maior ou igual a $1351,70 \mathrm{~mm}$.

De maneira geral e quantitativamente, o município de Sumé, localizado na porção do Cariri Ocidental, apresenta precipitações anuais mais elevadas que em São João do Cariri, localizado na porção do Cariri Oriental (quantis que definem as categorias $\mathrm{S}, \mathrm{N}$ e $\mathrm{C}$ ), corroborando com os estudos de Sena et al. (2014) e Alves et al. (2012). Porém, quando se analisa anos extremos de seca ou chuvosos (quantis ES, MS, MC e EC) há uma modificação nesse padrão, ou seja, os maiores volumes pluviométricos que definem esses eventos são em São João do Cariri (Tabela 3).

Tabela 3 - Classificação da intensidade da precipitação anual para Sumé e São João do Cariri.

\begin{tabular}{lc|c}
\hline & \multicolumn{2}{c}{ Intensidade da Precipitação (mm) } \\
\cline { 2 - 3 } \multicolumn{1}{c}{ Categorias } & Sumé & São João do Cariri \\
\hline Extremamente Seco (ES) & $\mathrm{p}(\mathrm{x})<27$ & $\mathrm{p}(\mathrm{x})<124,80$ \\
Muito Seco (MS) & $27 \leq \mathrm{p}(\mathrm{x})<248,68$ & $124,80 \leq \mathrm{p}(\mathrm{x})<214,44$ \\
Seco (S) & $248,68 \leq \mathrm{p}(\mathrm{x})<452,85$ & $214,44 \leq \mathrm{p}(\mathrm{x})<372,35$ \\
Normal (N) & $452,85 \leq \mathrm{p}(\mathrm{x})<697,89$ & $372,35 \leq \mathrm{p}(\mathrm{x})<658,91$ \\
Chuvoso (C) & $697,89 \leq \mathrm{p}(\mathrm{x})<799,67$ & $658,91 \leq \mathrm{p}(\mathrm{x})<786,55$ \\
Muito Chuvoso (MC) & $799,67 \leq \mathrm{p}(\mathrm{x})<890,20$ & $786,55 \leq \mathrm{p}(\mathrm{x})<1351,70$ \\
Extremamente Chuvoso (EC) & $\mathrm{p}(\mathrm{x}) \geq 890,20$ & $\mathrm{p}(\mathrm{x}) \geq 1351,70$ \\
\hline
\end{tabular}

Fonte: A autora, 2016.

A Figura 2 apresenta o percentual de anos em cada classe quantílica, do total precipitado anualmente. Para o município de Sumé os anos classificados como normais correspondem a $33,3 \%$ e para João do Cariri $28,6 \%$. As classes que abrangem as categorias dos anos que precipitam abaixo do normal (ES, MS, S), são iguais para os dois municípios, correspondendo a um total de $33,3 \%$ de toda a série estudada. Para as categorias (EC, MC e C), observa apenas uma diferença na classificação para anos chuvosos em que São João do Cariri apresenta uma porcentagem 4,8\% maior do que em Sumé, nas demais classificações os valores são idênticos.

É perceptível que a variabilidade em Sumé com relação à frequência observada dos anos chuvosos e secos é praticamente igual, sobressaindo os anos classificados normais, isso em termos quantitativos, como é sabido a variação temporal não é tão clara (SENA et al., 2014)

Em São João do Cariri, apesar de ser pequena, variação de 4,8\%, há uma quantidade maior de anos chuvosos. 


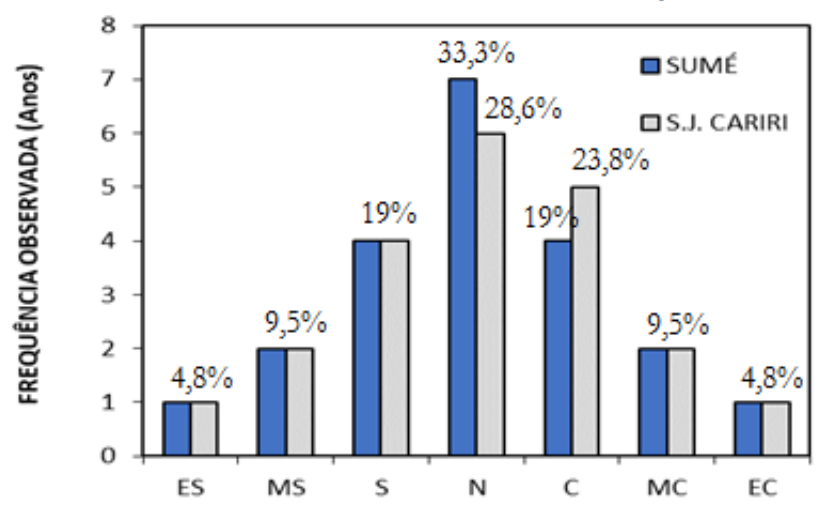

Legenda

Extremamente seco (ES)

Muito seco (MS)

Seco (S)

Normal (N)

Chuvoso (C)

Muito chuvoso (MC)

Extremamente chuvoso (EC)

Figura 2 - Frequência relativa das categorias de intensidade da precipitação para os municípios de Sumé e São João do Cariri (1995-2015). Fonte: A autora, 2016.

A partir da técnica dos quantis, a variabilidade interanual da precipitação (Figura 3) é possível identificar os anos mais discrepantes em termos de precipitação total anual. Em Sumé, os anos com precipitação mais extremas foi o ano de 2009, classificado como EC $(890,2 \mathrm{~mm})$ e o ano de 2012 como ES $(98,6 \mathrm{~mm})$. São João do Cariri apresentou os anos classificados como EC e ES em 2011 e 1998, com totais precipitados de 1351,7 mm e 124,8 mm, respectivamente. Esses anos atípicos representam uma redução de $32 \%$ e $83 \%$ e um aumento de até $52 \%$ e $254,4 \%$ em relação à climatologia de Sumé e de São João do Cariri, respectivamente.

Verifica-se a partir de 2000 até 2011 (um período relativamente extenso - 12 anos) a região não sofreu com escassez de chuva, percebe-se um aumento na frequência de chuvas com maior intensidade para ambos os municípios, esses resultados corroboram com os encontrados por Sena et al. (2014).

Nesse período, de 2000 a 2011, foi observado a presença de 4 eventos El Niño, sendo eles na categoria moderado e leve, e com GRADM positivo e neutro, tem -se também 6 eventos La Niña, sendo eles na categorias moderado, leve e forte, e o GRADM neutro, negativo e positivo, o que pode ter influenciado a precipitação da região, tendo em vista que nos anos de La Niña, o Oceano Atlântico estava em condições favoráveis, contribuindo com a pluviometria, destacando o ano de 2010/2011, ano de La Niña forte e GRADM positivo/neutro.

As únicas exceções ocorrem em 2007, para ambas as localidades, ano de El Niño moderado e GRADM neutro e 2003 para São João do Cariri, ano de El Niño moderado e o GRADM positivo, o que pode ter influenciado a pluviometria da região, as duas exceções foram classificadas na categoria S. 


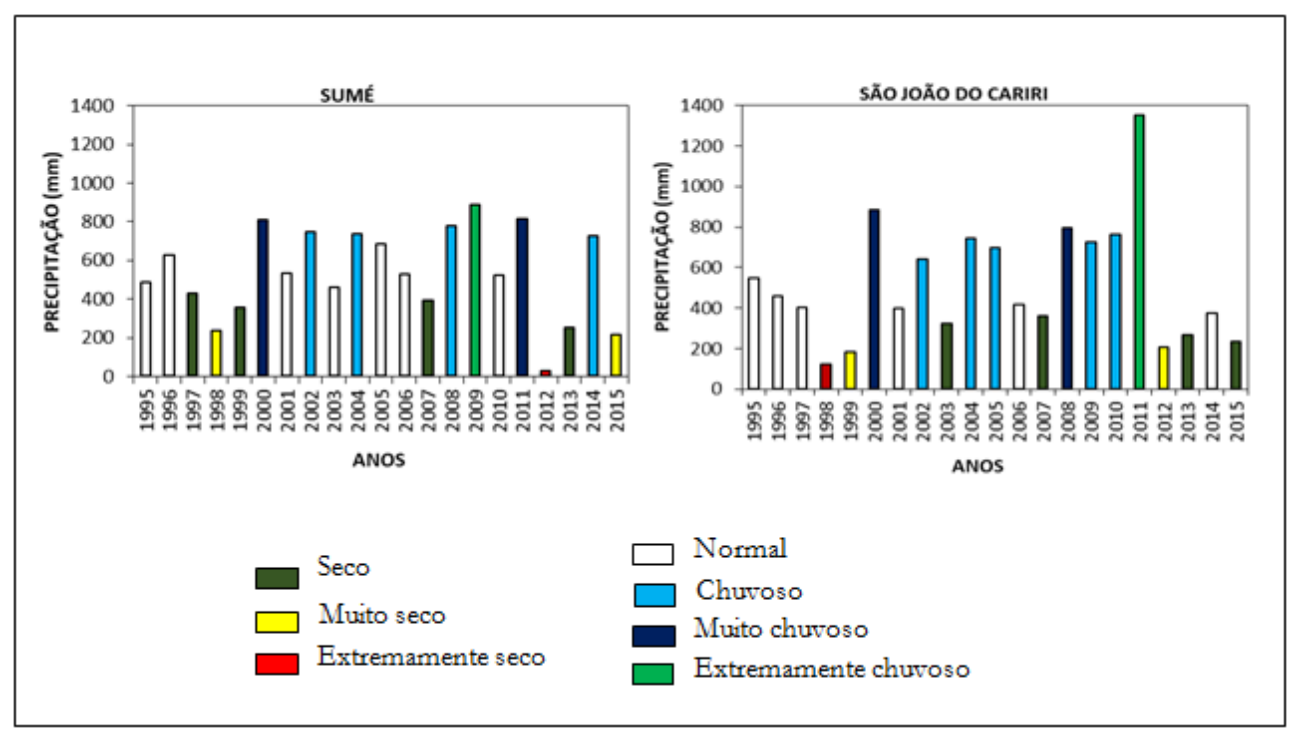

Figura 3 - Distribuição temporal da qualidade chuvosa para o município de Sumé e São João do Cariri para o período de 1995-2015. Fonte: A autora, 2016.

Após 2011 verifica-se as oscilações na precipitação na classificação ES, MS e S (categorias secas). As exceções são ano de 2014 para o município de Sumé (classificada com C) e o ano de 2014 em São João do Cariri (N). Marengo et al. (2016) afirma que, os anos compreendidos entre 2012 a 2015 são considerados o período de seca mais grave das últimas décadas na região semiárida. Corroborando com isso Vlaminck Saraiva, agrônomo e diretor da Emater comentou que "nesses quatros anos, a seca trouxe muitos prejuízos para os agricultores da Paraíba, as perdas na safra foram acima de $50 \%$, e na pecuária uma perda em torno de 40\%" (AGRO OLHAR, 2015). Além disso, Alexandre Magno, chefe do Departamento de Meteorologia da Agência Executiva de Gestão das Águas do Estado da Paraíba (AESA), explica que as chuvas nestes anos não foram suficientes para encher os reservatórios, nem para recuperar as reservas de água no subsolo, o que ocasionou um colapso na rede hídrica.

A análise dos oceanos também reforça essa diminuição da precipitação, com configurações, seja no Atlântico e/ou Pacífico, que inibem a precipitação na região, conforme visualizado na Tabela 4. No ano de 2014 o Oceano Atlântico com condições favoráveis e o Pacífico neutro pode ser uma justificativa para os anos as precipitações na categoria normal em São João do Cariri e chuvosa em Sumé. 
Tabela 4 - Eventos sobre os Oceanos no período de 2012 a 2015.

\begin{tabular}{c|c|c}
\hline \multirow{2}{*}{ Anos } & \multicolumn{2}{|c}{ OCEANOS } \\
\hline 2012 & Pacífico * Niña (M) & AtLÂNTICo \\
\hline 2013 & Neutro & Positivo \\
\hline 2014 & Neutro & Negativo \\
\hline 2015 & El Niño (L) & Negativo \\
\hline
\end{tabular}

Observação: As letras em parênteses referem-se à intensidade do evento em que, F - forte, M moderado e $\mathrm{L}$ - leve. * Os eventos sobre o Pacífico são inicializados no ano anterior, por exemplo, ano 2012 - evento 2011/2012, pois os ENOS se configuram no final do ano.

A Tabela 5 mostra a configuração dos eventos sobre os Oceanos Pacífico e Atlântico nos anos classificados nas categorias mais extremas, ou seja, MC e EC (Tabela 4a) e MS e ES (Tabela 4b). Percebe-se que nos anos de eventos chuvosos (categorias MC e EC) os oceanos apresentam características favoráveis, o oceano Pacífico com La Niña configurada e o Atlântico neutro ou com GRADM negativo, o que contribui com a precipitação conforme os estudos de Silva et al. (2012), Marengo et al. (2011), Galvíncio et al. (2010).

Tabela 5 - Eventos extremos de precipitação e condições sobre os oceanos Pacífico e Atlântico. (a) eventos chuvosos e (b) eventos secos.

(a)

\begin{tabular}{|c|c|c|c|}
\hline \multirow{2}{*}{ REGIÃo } & \multirow{2}{*}{$\begin{array}{l}\text { EVENTOS } \\
\text { CHUVOSOS }\end{array}$} & \multicolumn{2}{|c|}{ OCEANOS } \\
\hline & & PACÍfICo & ATLÂNTICO \\
\hline Sumé & $\begin{array}{l}2000 \\
2009 \\
2011\end{array}$ & $\begin{array}{l}\text { La Niña (F) } \\
\text { La Niña (L) } \\
\text { La Niña (F) }\end{array}$ & $\begin{array}{l}\text { Neutro } \\
\text { Negativo } \\
\text { Neutro }\end{array}$ \\
\hline $\begin{array}{l}\text { São João do } \\
\text { Cariri }\end{array}$ & $\begin{array}{l}2000 \\
2008 \\
2011\end{array}$ & $\begin{array}{l}\text { La Niña (F) } \\
\text { La Niña (L) } \\
\text { La Niña (F) }\end{array}$ & $\begin{array}{l}\text { Neutro } \\
\text { Negativo } \\
\text { Neutro }\end{array}$ \\
\hline
\end{tabular}

(b)

\begin{tabular}{|c|c|c|c|}
\hline \multirow{2}{*}{ REGIÃo } & \multirow{2}{*}{$\begin{array}{c}\text { EVENTOS } \\
\text { SECOS }\end{array}$} & \multicolumn{2}{|c|}{ OCEANOS } \\
\hline & & PACÍfICO & AtLÂntico \\
\hline Sumé & $\begin{array}{l}1998 \\
2012 \\
2015\end{array}$ & $\begin{array}{l}\text { El Niño (F) } \\
\text { La Niña (M) } \\
\text { El Niño (L) }\end{array}$ & $\begin{array}{c}\text { Neutro } \\
\text { Positivo } \\
\text { Negativo }\end{array}$ \\
\hline $\begin{array}{l}\text { São João do } \\
\text { Cariri }\end{array}$ & $\begin{array}{l}1998 \\
1999 \\
2012\end{array}$ & $\begin{array}{l}\text { El Niño (F) } \\
\text { La Niña (F) } \\
\text { La Niña (M) }\end{array}$ & $\begin{array}{l}\text { Neutro } \\
\text { Neutro } \\
\text { Positivo }\end{array}$ \\
\hline
\end{tabular}

Observação: As letras em parênteses na tabela 4 (a e b) referem-se à intensidade do evento em que, $\mathrm{F}$ - forte, $\mathrm{M}$ - moderado e $\mathrm{L}$ - leve. 
Não é tão clara a contribuição nos anos de eventos secos extremos (categorias MS e ES), em que nota-se nos anos de 2015 (em Sumé) e 1999 (em São João do Cariri) com configurações sobre um dos oceanos que contribui com a precipitação, ou seja, é necessária analises mais detalhada, por exemplo, mês a mês para investigar o que aconteceu incluindo sistemas atmosféricos que podem inibir a precipitação. Nos outros anos segue o padrão da literatura onde os eventos El Niño configurado no Pacífico ou Gradiente positivo no Atlântico inibe as precipitações (Xavier et al., 2003 e Santos e Brito, 2007). Segundo Marengo et al. (2011) as consequências do El Niño são mais devastadoras, visto que a área possui uma fraca infraestrutura hídrica, além de ser carente de políticas públicas que mitiguem o problema causado pela instabilidade pluviométrica.

\section{ESTUDO DE CASO: CONSEQUÊNCIAS DOS EVENTOS EXTREMOS SECO (1998) E CHUVOSO (2011)}

Em 1998, classificado como MS para o município de Sumé e ES para São João do Cariri, a região do Cariri foi a mais castigada pela seca, segundo o relatório divulgado pelo Laboratório de Meteorologia Recursos Hídrico e Sensoriamento Remoto (LMRS-PB). O El Niño configurado neste ano em conjunto com a alta vulnerabilidade da população e com a falta de políticas públicas, trouxe consequências desastrosas em toda a região. O resultado desestabilizou a economia onde foi observado que famílias migraram da zona rural para a urbana. No campo, uma significativa parcela dos rebanhos morreu de fome e/ou de sede, sendo decretado estado de calamidade pública em todos os municípios. Para amenizar/solucionar a situação, foram aplicadas medidas paliativas como: distribuição de cestas básicas, abertura de frentes de trabalho e carros-pipa tiveram de abastecer com água as comunidades rurais e urbanas (Sousa, 2007).

Devido à instabilidade climática da região, que impõe riscos à agricultura de sequeiro, na maioria das vezes se planta muito e se colhe pouco, sendo o prejuízo econômico ainda maior em anos de secas recorrentes. Os dados da área plantada e colhida de milho e feijão (Tabela 6) no ano de 1998 apresentaram resultados semelhantes aos de Silva Neto (2004), que trabalhando nos municípios de Sumé, Prata, Ouro Velho e Amparo, resultaram a uma não produção, a nível zero a produção de milho e feijão, provocando a indisponibilidade da base energética das famílias rurais. 
Tabela 6 - Quantidade de área plantada e colhida (em hectares) para as culturas do milho e feijão em Sumé e São João do Cariri.

\begin{tabular}{|c|c|c|c|c|}
\hline \multirow[b]{2}{*}{ Município } & \multirow[b]{2}{*}{ Cultura } & \multirow{2}{*}{$\begin{array}{c}\text { Área } \\
\text { Plantada e } \\
\text { colhida (ha) }\end{array}$} & \multicolumn{2}{|c|}{ Ano } \\
\hline & & & 1998 & 2011 \\
\hline \multirow{4}{*}{ Sumé } & \multirow{2}{*}{ Feijão } & Área Plantada & - & 1000 \\
\hline & & Área Colhida & - & 1000 \\
\hline & \multirow{2}{*}{ Milho } & Área Plantada & - & 1000 \\
\hline & & Área Colhida & - & 1000 \\
\hline \multirow{4}{*}{$\begin{array}{l}\text { São João } \\
\text { do Cariri }\end{array}$} & \multirow{2}{*}{ Feijão } & Área Plantada & 100 & 1100 \\
\hline & & Área Colhida & 0 & 1100 \\
\hline & \multirow{2}{*}{ Milho } & Área Plantada & 100 & 1200 \\
\hline & & Área Colhida & 0 & 1200 \\
\hline
\end{tabular}

Fonte: IBGE, 2016.

No ano de 2011, classificado como um ano MC para Sumé e EC para São João do Cariri, toda a área plantada foi colhida. As culturas de feijão e milho dependem totalmente da evolução das precipitações dentro do período chuvoso. O ano de 2011 foi ano de La Niña forte e GRADM neutro, isto significa que, apenas o Oceano Pacífico está influenciando a precipitação da região.

A pecuária extensiva é a principal atividade econômica do Cariri. Segundo o IBGE (2010) o destaque principal fica para os rebanhos de caprinos, seguido dos bovinos, sendo o último responsável por grande parte da renda dos pequenos produtores, além de médios e grandes agricultores, outros que aparecem na lista são a ovinocultura e os suínos.

Comparando o efetivo pecuário (Tabela 7), a perda ou ganho foi realizado a partir do total anual de cada rebanho, observa-se que nos anos de 1997/1998 no município de Sumé ocorreu uma redução de bovino e ovino, o rebanho do tipo caprinos e suíno apresentou um aumento de 57\%. Esse aumento pode estar associado com a resistência dos animais de se adaptarem às condições climáticas, de aridez e de limitações topográficas. Já São João do Cariri apresentou uma redução em todo o rebanho. Tendo em vista, que o ano de 1997/1998 foi ano de El Niño forte e GRADM positivo, afetando assim o suporte forrageiro e a disponibilidade de água para os animais.

Tabela 7 - Efetivo pecuário por município e por tipo de rebanho.

PECUÁRIA

\begin{tabular}{c|l|c|c|c|c}
\hline \multirow{2}{*}{ Município } & \multirow{2}{*}{ Rebanho } & \multicolumn{4}{|c}{ Anos } \\
\cline { 3 - 7 } & & $\mathbf{1 9 9 7}$ & $\mathbf{1 9 9 8}$ & $\mathbf{2 0 1 0}$ & $\mathbf{2 0 1 1}$ \\
\hline \multirow{4}{*}{ Sumé } & Bovino & 10.534 & 6.480 & 9.000 & 10.000 \\
\cline { 2 - 6 } & Caprino & 9.323 & 17.646 & 17.200 & 15.400 \\
\cline { 2 - 6 } & Ovino & 10.936 & 4.720 & 7.800 & 8.900 \\
\cline { 2 - 6 } & Suíno & 807 & 1.268 & 1.845 & 1.650 \\
\hline \multirow{4}{*}{$\begin{array}{c}\text { São João do } \\
\text { Cariri }\end{array}$} & Bovino & 8.819 & 4.410 & 6.100 & 7.316 \\
\cline { 2 - 6 } & Caprino & 16.774 & 6.262 & 11.020 & 9.500 \\
\cline { 2 - 6 } & Ovino & 14.576 & 3.996 & 5.560 & 6.450 \\
\cline { 2 - 6 } & Suíno & 487 & 388 & 460 & 490 \\
\hline
\end{tabular}

Fonte: IBGE, 2016. 
Nos anos de 2010/2011 enquadrados em uma das categorias chuvosa, nota-se um aumento no rebanho bovino e ovino em ambos os municípios e uma redução principalmente no rebanho caprino.

Um dos principais problemas que agrava a situação dos agricultores e pecuaristas da região é a ausência de recursos financeiros que poderia amenizar a ausência de área de pastagens com o uso de insumos agropecuários e irrigação. Por esse motivo, em anos que o fenômeno El Niño ocorre, as perdas são ainda maiores em termos de produção. Dentre as estratégias adotadas pelos agropecuaristas para mitigar os efeitos da estiagem estão a substituição da pastagem natural pela pastagem artificial, além da inserção de animais mais adaptados às condições áridas, o que aumenta a participação destes produtores na economia local (Sousa et al., 2008).

Não obstante, vale ressaltar a necessidade do auxílio através de programas e políticas públicas sociais do governo federal, estadual e municipal visando melhorar as condições de sobrevivência dos moradores locais, "caririzeiros", como se autodenominam. Além da implantação de tecnologias sociais voltadas à produção de alimentos e à pecuária sustentável, a erradicação da pobreza, a eliminação das desigualdades regionais, uma gestão assertiva para o uso das águas e a mitigação da poluição dos corpos hídricos tão escassos, porém extremamente necessários.

\section{CONCLUSÃO}

A técnica dos quantis mostrou-se eficiente na identificação de anos extremamente chuvosos e secos. Os anos considerados normais apresentaramse com maior frequência. Destaca-se no período de 2000 a 2011 a predominância, quase em sua totalidade, de eventos nas categorias chuvosas e, após 2011 um período de secas intensas em Sumé e São João do Cariri, com exceção do ano de 2014.

A influência dos oceanos em anos de eventos extremos de precipitação (EC, MC, ES e MS) nos município em estudo, revelou mais forte nos anos chuvosos com a presença do evento La Niña configurado no Pacífico e o gradiente negativo ou condições neutras no Atlântico. Nos anos com precipitação reduzida, apesar da influência dos oceanos Pacífico e Atlântico com configuração do El Niño e gradiente positivo, alguns anos apresentou o evento La Niña.

O impacto dos eventos extremos de chuvas na agropecuária é bem visível. Nos anos secos a agricultura, que na região é praticamente de subsistência, sofre com perda total ou intensa. Nos anos chuvosos normalmente a área plantada é colhida. Em se tratando da pecuária, percebe-se que os bovinos e ovinos são os que mais sofrem no período de seca, com diminuição da quantidade de cabeças e nos anos chuvosos os rebanhos que são mais impactados são os caprinos.

\section{AGRADECIMENTOS}

À Coordenação de Aperfeiçoamento de Pessoal de Nível Superior CAPES, pela concessão da bolsa de estudo durante o mestrado. 


\section{REFERÊNCIAS BIBLIOGRÁFICAS}

AESA, 2018. Disponível em: http://www.aesa.pb.gov.br/aesawebsite/meteorologia-chuvas/climatologia/.Acesso em 25 jul. 2018.

Agro Olhar, 2015. Disponível em: <http://www.olhardireto.com.br/agro/noticias/exibir.asp?noticia=seca-dificultacada vez-mais-a-vida-dos-agricultores-sertanejos-daparaiba\&edt $=9 \& i d=19274>$. Acesso em $19 \mathrm{dez} .2016$.

ALVES, T. L. B.; AZEVEDO, P. V.; FARIAS, A. A. Comportamento da precipitação pluvial e sua relação com o relevo nas microrregiões do Cariri Oriental e Ocidental do estado da Paraíba. Revista Brasileira de Geografia Física, v.08, n. 06, p. 1601-1614, 2012.

ALMEIDA, H. A. DE.; FREITAS, R. C.; SILVA, L. DA. Determinação de períodos secos e chuvosos em dias microrregiões da Paraíba através da Técnica dos Quantis. Revista de Geografia (UFPE), v. 30, n. 1, p. 217-232, 2013.

BARBOSA, J.P.M. Estudo sobre a evolução dos eventos extremos de precipitação no setor paulista da serra do mar. In: SIMPÓSIO BRASILEIRO DE RECURSOS HÍDRICOS, 17., 2007, São Paulo. Anais... . São Paulo:ABRH, 2007. P. 1-21.

CALVETTI, L.; BENETI, C.; ANTUNES, R.L.; OLIVEIRA, A.C. Validação de estimativas de precipitação por radar e satélite: análise de relações ZR e integração com pluviômetros. In: SIMPÓSIO BRASILEIRO DE RECURSOS HÍDRICOS, 18., 2009, Campo Grande. Anais... . Campo Grande: ABRH, 2009, p.1-14.

COAN, B. DE P.; BACK, A. J.; BONETTI, A. V. Precipitação mensal e anual provável no estado de Santa Catarina. Revista Brasileira de Climatologia, [s.l.], v. 15, p. $122-142$, abr. 2015.

CPC - Climate Prediction Center. Disponível em: < http://www.cpc.ncep.noaa.gov/>. Acesso em 15 de jan de 2017.

FARIAS, A. A.; SOUSA, F. A. S.; MORAES NETO, J. M.; ALVES, A. S. Secas e seus impactos no município de Boqueirão, PB. Revista Ambiente \& Água, Taubaté, vol.12, n.2, 2017.

GALVÍNCIO, J. D.; DA SILVA, D.F.; NÓBREGA, R. S. Mudanças Climáticas e recursos hídricos: aplicações no estado de Pernambuco. 1 ed. Recife: UFPE, 2010, v.1, p.27-55.

LOUREIRO, R. S. DE.; SARAIVA, J. M.; SARAIVA, I.; SENNA, R. C.; FREDO, A. S. Estudo dos eventos extremos de precipitação ocorridos em 2009 no estado do Pará. Revista Brasileira de Meteorologia, São Paulo, v. 29, n. esp., p. 83-94, 2014.

LUCENA, D.B.; GOMES FILHO, M.F.; SERVAIN, J. Avaliação do Impacto de Eventos Climáticos Extremos nos Oceanos Pacífico e Atlântico sobre a Estação Chuvosa no Nordeste do Brasil. Revista Brasileira de Meteorologia, v.26, n. 2, p. $297-312,2011$.

IBGE - Instituto Brasileiro de Geografia Estatística. Disponível em: 
<http://www2.sidra.ibge.gov.br/bda/tabela/listabl.asp?c $=1612 \& z=t \& o=11>$. Acesso em: 20 dez. 2016.

IBGE - Instituto Brasileiro de Geografia Estatística. Disponível em: <http://www2.sidra.ibge.gov.br/bda/tabela/listabl.asp?z=t\&c=73>. Acesso em: 20 de dez. 2016.

MARENGO, J. A.; ALVES, L. M.; BESERRA, E. A.; LACERDA, F. F. Variabilidade e mudanças climáticas no semiárido brasileiro. In: Medeiros, S. S.; Gheyi, H. R.; Galvão, C. de O.; Paz, V. P. da S. Recursos hídricos em regiões áridas e semiáridas. Campina Grande: INSA, 2011. p. 383-422.

MARENGO, J. A.; CUNHA, A.P.; ALVES, L.M. "A seca de 2012 -15 no semiárido do Nordeste do Brasil no contexto histórico" (2016). Disponível em: <http://climanalise.cptec.inpe.br/ rclimanl/revista/pdf/30anos/marengoetal.pdf >. Acesso em 10 jan. 2017.

MARENGO, J. A. Mudanças climáticas globais e seus efeitos sobre a biodiversidade: caracterização do clima atual e definição das alterações climáticas para o território brasileiro ao longo do século XXI. Brasília, DF: MMA, 2006. 202 p. il. (Biodiversidade, 26).

MOLION, L. C. B.; BERNARDO, S. de O. Uma revisão da dinâmica das chuvas no nordeste brasileiro. Revista Brasileira de Meteorologia, v. 17, n. 1, p. 1-10, 2002.

MOURA, M. S. B.; GALVINCIO, J. D.; BRITO, L. T. L.; SOUZA, L. S. B.; SÁ, I. S.; SILVA, T. G. F. Clima e água de chuva no Semi-Árido. 2007. Disponível em: Acesso em: 12 de abril de 2017.

NÓBREGA, J. N.; SANTOS, C. A. C.; GOMES, O. M.; BEZERRA, B. G.; BRITO, J. I. B. Eventos extremos de precipitação nas mesorregiões da Paraíba e suas relações com a TSM dos Oceanos Tropicais. Revista Brasileira de Meteorologia, v.29, n.2, p. 197 - 208, 2014.

PEREIRA, V. DA C.; SOBRINHO, J. E.; OliVEIRA, A. D.; MELO, T. K.; VIEIRA, R. Y. M. Influência dos eventos El Niño e La Niña na precipitação pluviométrica de Mossoró-RN. Enciclopédia Biosfera - Centro Científico Conhecer, Goiânia, v. 7, n. 12, p. 1-13, 2011.

ROPELEWSKI, C. F.; HALPERT, M. S. Global and regional scale precipitation patterns associated with El Niño/Southern Oscillation. Monthly Weather Review, [s.1.], v.115, p. 1606-1626, 1987.

SANTOS, C. A. C.; BRITO, J. I. B. Análise dos índices de extremos para o semiárido do Brasil e suas relações com TSM e IVDN. Revista Brasileira de Meteorologia, [s.I.], v. 22, n. 3, p. 303-312, 2007.

SENA, J. P. O.; MELO, J. S.; LUCENA, D. B.; MELO, E. C. S. Comparação entre dados de chuva derivados do Climate Prediction Center e observados para a região do cariri paraibano. Revista Brasileira de Geografia Física. [s.I.], v. 2, p. 412-420, 2012.

SENA, J.P.O.; MELO, J.S.; LUCENA, D.B.; MELO, E.C.S. Caracterização da precipitação na microrregião do Cariri Paraibano por meio da Técnica dos Quantis. Revista Brasileira de Geografia Física, v. 7. n.5, p. 871-879, 2014. 
SILVA, D.F.S.; SOUSA, A.B.; MAIA, L.M.; RUFINO, L.L. Efeitos da associação de eventos de ENOS e ODP sobre o Estado do Ceará. Revista de Geografia, v.29, n.2, 2012.

SILVA NETO, A. F. da. Estudo das vulnerabilidades agro-ambientais frente aos eventos enos e a construção social dos riscos em municípios do cariri ocidental Paraíba: uma análise comparativa. 2004. 206 f. Tese (Doutorado) - Curso de Recursos Naturais, Universidade Federal de Campina Grande, Campina Grande, 2004.

SILVA, V. P. R.; SARAIVA, F. A. M.; MELO, E. C. S.; ARAUJO, J. A. P.; CORREIA, A. M. Influência do fenômeno El Niño e dipolo do Atlântico no regime de chuvas do Estado da Paraíba. In: CONGRESSO BRASILEIRO DE AGROMETEOROLOGIA, 11., e REUNIÃO LATINO-AMERICANA DE AGROMETEOROLOGIA, 2., Florianópolis. Anais... . Florianópolis: SBAgro, 1999.

SOUSA, R. F. de. Terras agrícolas e o processo de desertificação em municípios do semiárido paraibano. 2007.180 f. Tese (Doutorado) - Curso de Engenharia Agrícola, Centro de Tecnologia e Recursos Naturais, Universidade Federal de Campina Grande, Campina Grande, 2007.

SOUSA, R. F.; BARBOSA, M. P.; TERCEIRO NETO, C. P. C.; CARVALHO, A. P.; LIMA, A. N. Uso de geotecnologias no diagnóstico da degradação das terras do município de São João do Cariri - PB. Revista Caatinga, Mossoró, v. 21, n. 1, p. 204-210, 2008.

SOUZA, B. I. de. Cariri paraibano: do silêncio do lugar à desertificação. Porto Alegre: UFRS, 2008. 198 p. Tese Doutorado - Curso de Geografia, Instituto de Geociências, Universidade Federal do Rio Grande do Sul.

TRENBERTH, K.E. The definition of El Niño. Bulletin American Meteorological Society, 78, 2771-2777, 1997.

WAINER, I. O papel do Oceano Atlântico no clima. Disponível em: http://oc2.io.usp.br/index.php?option=com_content; view=article; id=13:0papel-do-oceano-atlantico-no-clima; catid=42: pesquisa, Itemid=30. Acesso: 15 jan.2017.

XAVIER, T. M. B. S.; XAVIER, A. F. S.; DIAS, M. A. F. S.; DIAS, P. L. S. Interrelações entre eventos ENOS (ENSO), a ZCIT (ITCZ) no Atlântico e a chuva nas bacias hidrográficas do Ceará. Revista Brasileira de Recursos Hídricos, [s.l.], v. 8, p. 111-126, 2003.

XAVIER, T. DE M. B. S; XAVIER, A. F. S; ALVES, J. M. B. Quantis e eventos extremos: aplicações em ciências da terra e ambientais. Fortaleza: RDS, 2007. $278 \mathrm{p}$.

ZANELLA, M. E. Eventos pluviométricos intensos em ambiente urbano: Fortaleza, episódio do dia 29/01/2004. In: Silva, J. B. da; Dantas, E. W. C.; Zanella, M. E.; Meireles, A. J. de A. (Org.). Litoral e sertão: natureza e sociedade no nordeste brasileiro. Fortaleza: Expresso Gráfica, 2006. P. 1995207. 